\title{
Automatic Petrol and Diesel Engine Sound Identification Based on Machine Learning Approaches
}

\author{
Halim Frederick ${ }^{1}$, Astuti Winda ${ }^{1, *}$, and Mahmud Iwan Solihin ${ }^{2}$ \\ ${ }^{1}$ Automotive and Robotics Program, Computer Engineering Department, BINUS ASO School of \\ Engineering, Bina Nusantara University, Jakarta, Indonesia 11480 \\ ${ }^{2}$ Faculty of Engineering, Technology and Built Environment, UCSI University, Cheras, Kuala \\ Lumpur 56000, Malaysia
}

\begin{abstract}
Petrol and diesel engine have a significantly different way to convert chemical energy into mechanical energy. In this work, the intelligent system approach is used to automatically identify the type of engine based on the sound of the engine. The combination of signal processing and machine learning technique for automatic petrol and diesel engine sound identification is presented in this work. After a signal preprocessing step of the engine sound, a Fast Fourier Transform (FFT)-based frequency characteristic modelling technique is applied as the feature extraction method. The resulting features extracted from the sound signal, in the form of frequency in the FFT matrix, are used as the inputs for the machine learning, the Support Vector Machine (SVM), step of the proposed approach. The experiment of FFT with SVMbased diesel and petrol engine sound identification has been carried out. The results show that the proposed approach produces a good accuracy in the relatively short training time. Experimental results show the training and testing accuracy of $100 \%$ and $100 \%$ respectively. They confirm the effectiveness of the proposed intelligent automatic diesel and petrol engine sound identification based on Fast Fourier Transform (FFT) and Support Vector Machines (SVMs).
\end{abstract}

Key words: Engine sounds, fast fourier transform, support vector machine.

\section{Introduction}

Recently, the growth of industrial revolution 4.0 in the autonomous vehicle sector is experiencing rapid growth. The advance autonomous technology involve many aspect in the vehicle, such as autonomous self driving, and full autonomous self driving [1-4] . One of the importance aspect in advance autonomous vehicle is engine mainatance. The engine maintainace system plays an important rule in vehicle system, since the engine is the main part in the automotive. One of the problem which could happen in the engine maintance is misfueling. This problem can effects seriuous problem in the engine [5].

There are some of the differences characteristic of the diesel and petrol engine. The condition of diesel nozzles is bigger than the filler neck on petrol cars. Also, there is a plate under the neck to prevent any intrusion but the small petrol nozzle, which was designed to prevent drivers from putting leaded (big nozzle too) petrol in the first place. Diesel is heavier than the gasoline, and much more "oily". It needs pressure to be ignited and does not evaporate as gasoline do. What happens after putting diesel on a tank is, diesel sank and injectors feed the engine a load of diesel. Furthermore, putting petrol on a diesel engine, is

*Corresponding author: wastuti@, binus.edu 
much more complicated. A diesel car can be filled with petrol rather easily, as the filler neck allows all nozzle kinds smaller than the diesel nozzle inside (which is basically every nozzle available) [5].

However, misfueling diesel to petrol engine or petrol to diesel engine is one of the most common mistake that is generally fatal to the engine system. Petrol and diesel engine have a significantly different way to convert chemical energy into mechanical energy. Diesel engine relies on the high compression ratio of its combustion chamber to ignite a mixture of diesel inside the chamber, while petrol engine uses spark plug to ignite a mixture of petrol in its much lower compression ratio combustion chamber. The working mechanism of each engine system fits to the chemical characteristic of the designated fuel, which will result in engine system damage if misfueled. In this work, the intelligent system approach is used to automatically identify the type of engine based on the sound of the engine.

Feature extraction and intelligent system are the most main stages in this work. There are many features had been proposed such as Mel-frequency cepstral coefficient (MFCC) [6], linear predictive coding (LPC), linear predictive ceptral coefficient (LPCC) [7] and formant frequency [8]. Furthermore, in the Intelligent system process, many techniques been proposed in the literature such as support vector machine [9], multi-layers neural network [10] and fuzzy logic [11].

The combination of signal processing and machine learning technique for automatic petrol and diesel engine sound identification is presented in this work. After a signal preprocessing steps of the engine sound, a Fast Fourier Transform (FFT) technique is applied as the feature extraction method. The resulting features extracted from the sound signal, in the form of significant frequency in the FFT matrix, are used as the inputs for the machine learning, the Support Vector Machine (SVM), step of the proposed approach.

\section{Literature review}

This section presents, the basic general process consist of two important parts, namely feature extraction and Intelligent system. Sound is recorded using a microphone. The next process of the recorded sound will be extracted by feature extraction. In this process, the extracted data is the use as input to the intelligent system part. Finally, the sound engine recognition to make the training process for recognizing the type of fuel of the automobile.

\subsection{Fast fourier transform}

Fast Fourier Transform used as feature extraction method for sound processing. The Fast Fourier Transform of $f(x)$ is the function of $F(\omega)$ is explained as equation below [15]:

$F(\omega)=\int_{-\infty}^{\infty} f(x) e^{-i \omega x} d x$

Where $i=\sqrt{-1}$ and $e^{i \theta}=\cos \theta+\sin \theta$

The absolute value resulting by FFT algorithm is obtained the frequency of the FFT. The step begins with frequency determination from the fast fourier transform (FFT) algorithm. The absolute value is determined. The logarithmic plot of FFT, referred to spectrum, is obtained. If the log amplitude spectrum contains many regularly spaced harmonics, then the FFT spectral will show peaks corresponding to the spacing between the harmonics as show in Figure 1. 


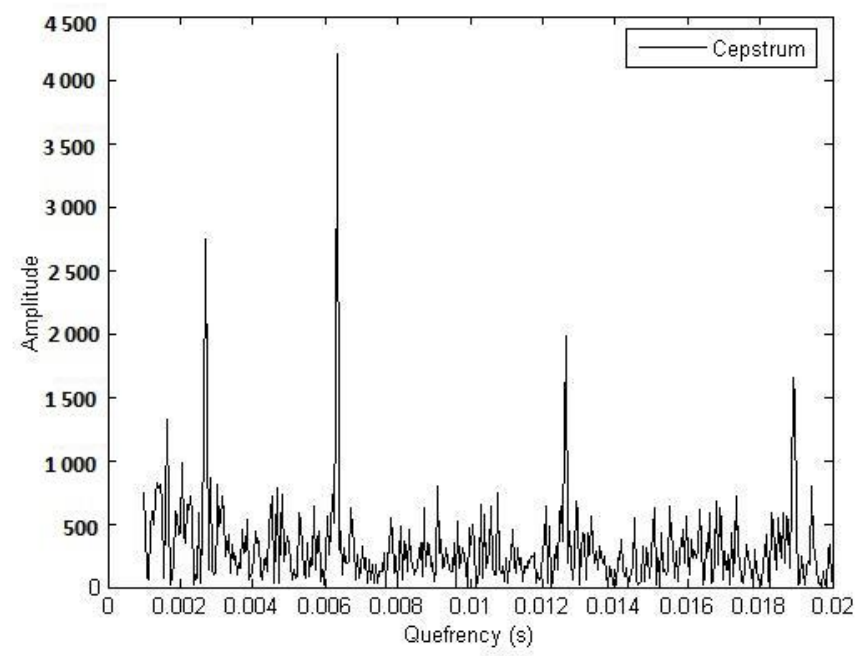

Fig. 1. The frequencies of the signal

The significant frequencies as shown in Figure 1, are obtained as the characteristic frequency of the sounds. The most significant frequency is used to find the best model coefficient for the sampled engine sound signal.

\subsection{Support vector machine (SVM)}

The SVM mapping non linear data into high dimentional feature space in linear form. Fig. 2 shows linearly-separable data with no possibility of miss-classification data.

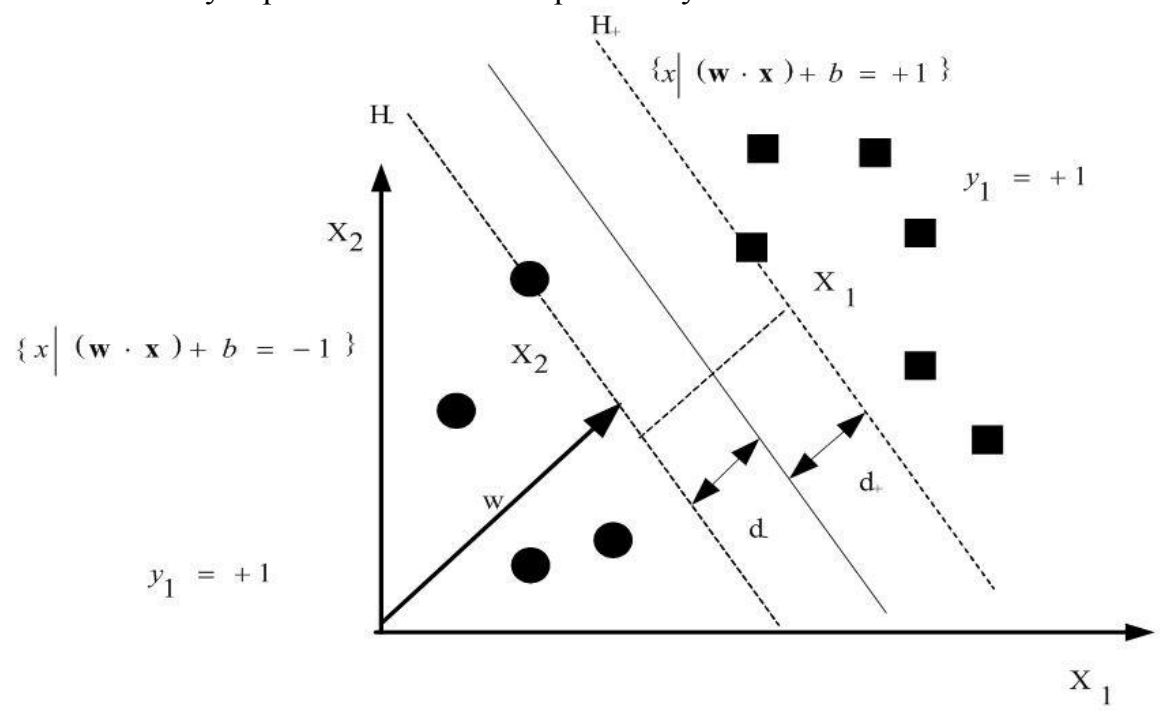

Fig. 2. SVM with Linear separable data.

In the linear separable case, there exists a separating hyperplane, as shown in Equation 2 whose function is;

$w \bullet x+b=0 \quad w \in R^{N}, b \in R$ 
For optimized linear division a hyperplane is constructed to separate the two classes as shon in Equation 3 [13] which implies:

$$
y_{i}(w \bullet x+b=0) \geq 1, i=1, \ldots, N
$$

By minimizing $\|\mathbf{w}\|$ subject to this constrain, the SVM approach tries to find a unique separating hyperplane. Here $\|\mathbf{w}\|$ is the Euclidean norm of $\mathbf{w}$, and the distance between the hyperplane and the nearest data points of each class is $1 /\|\mathbf{w}\|$. Using Lagrange multiplier $\alpha_{i}$, the SVM training procedure amounts to solving a convex quadratic problem (QP). The solution is a unique globally optimization result, which has following properties as shown in Equation 4:

$$
w=\sum_{i}^{N} \alpha_{i} y_{i} x_{i}
$$

provided $\alpha_{i}$ is not equal to zero, $x_{i}$ is called the support vectors. When SVM is trained, a decision can be obtained by comparing each new example $\mathrm{x}$ with only the support vector $\left\{\mathrm{x}_{i}\right\}, i \in \mathrm{SV}$, as shown in Equation 5:

$$
y=\operatorname{sign}\left(\sum_{i \in S V} \alpha_{i} y_{i}\left(x_{i} \bullet x^{T}\right)+b\right)
$$

\section{Proposed SVM-based engine sound Identification system}

As shown in Figure 3, the fuel classification system consists of three main functions: (i) pre-processing; (ii) Feature Extraction; (iii) intelligent system. Pre-processing consists of pre-emphasis and windowing. The preprocessing signal is the extracted based on FFT technique. The extracted feature is then identify used SVM-based intelligent system.

Engine sound signal

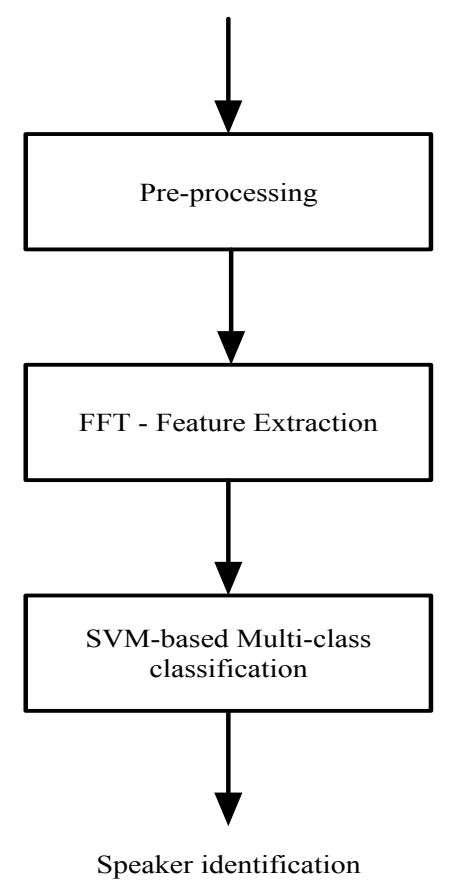

Fig. 3. Overall proposed speaker identification model. 


\section{Experimental work}

This section presents the performance of the proposed to Automatic petrol and diesel engine sound identification based on parametric modeling technique and machine learning approach. This section consists of three important subsections, they are experimental setup, experimental result and experimental analysis.

\subsection{Experimental Design}

Figure 4 shown the experimental design of speaker identification system. The sound of the engine is recorded using a microphone. The recorded sound of the engine then sent to the PC thought 16 bits A/D with sampling frequency $44 \mathrm{KHz}$, all the signal is converted in the PC with processor $1.5 \mathrm{Mhz}$ Pentium as shown in the Table 2 . The sound of the engine signal is recorded using a microphone and then the recorded signal is sent to the computer through an analog to digital (A/D) card.

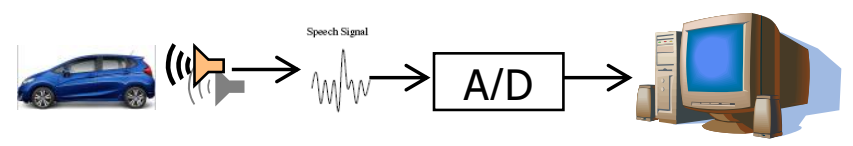

Fig. 4. Automatic petrol and diesel engine sound identification.

The system identifies six different automotive engine sound from six different cars with two types of patrol and diesel, respectively.

Table 2. Specification of the system

\begin{tabular}{|l|l|}
\hline Processor & $1.5 \mathrm{MHz}$, Intel \\
\hline A/D & $16 \mathrm{bits} \mathrm{A} / \mathrm{D}$ \\
\hline Frequency sampling & $22 \mathrm{KHz}$ \\
\hline
\end{tabular}

\subsection{Experiment result}

In order to evaluate the effectiveness of the proposed intelligent system on automatic petrol and diesel identification system, the proposed system is installed. In this proposes system the specification microphones. The sound is recorded and captured. The raw recorded petrol signal and diesel as shown in Figure $5 \mathrm{a}$ and Figure $5 \mathrm{~b}$, respectively.

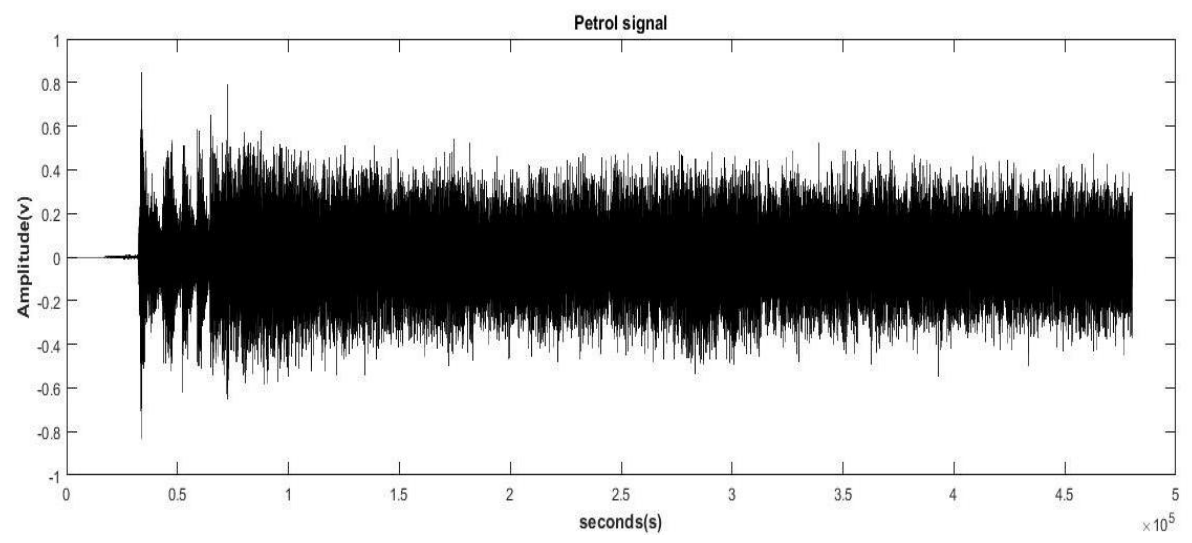

(a) Petrol Signal 


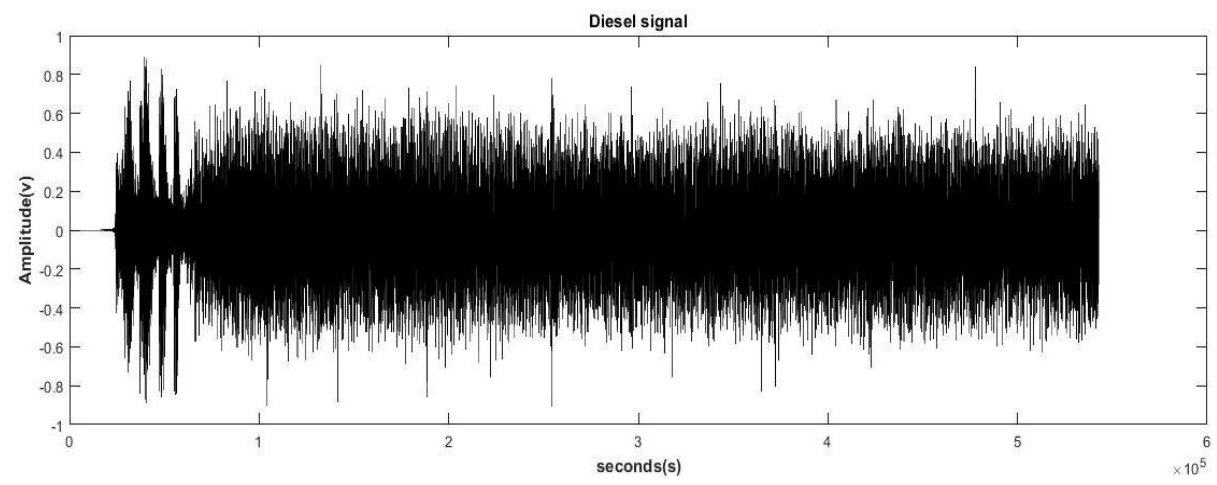

(b) Diesel Signal

Fig. 5. Raw petrol and diesel signal.

Once the raw signal is recorded, then the FFT method is applied to the raw signal, as shown in Figure 6. The FFT result of the FFT on Petrol and Diesel signal. Four significant frequencies of each signal are then obtained as the characteristics of petrol and diesel, respectively.

From 16 samples peak amplitude from four different vehicles of each type, petrol and diesel, respectively are obtained. Four different samples of each vehicle of different fuel types are used to train the system. Furthermore, the other four different samples of each of the vehicles samples are applied to test the system. In this experiment The SVMs based method is applied to perform the classification process of the training phases. A Polynomial kernel function is used. The training classification rate for these two feature based resulting $100 \%$ correct and the testing classification rate lies on $100 \%$ for formant frequency with radial basis function kernel, as shown in Table. This result shows that binary -class classification performs good result.

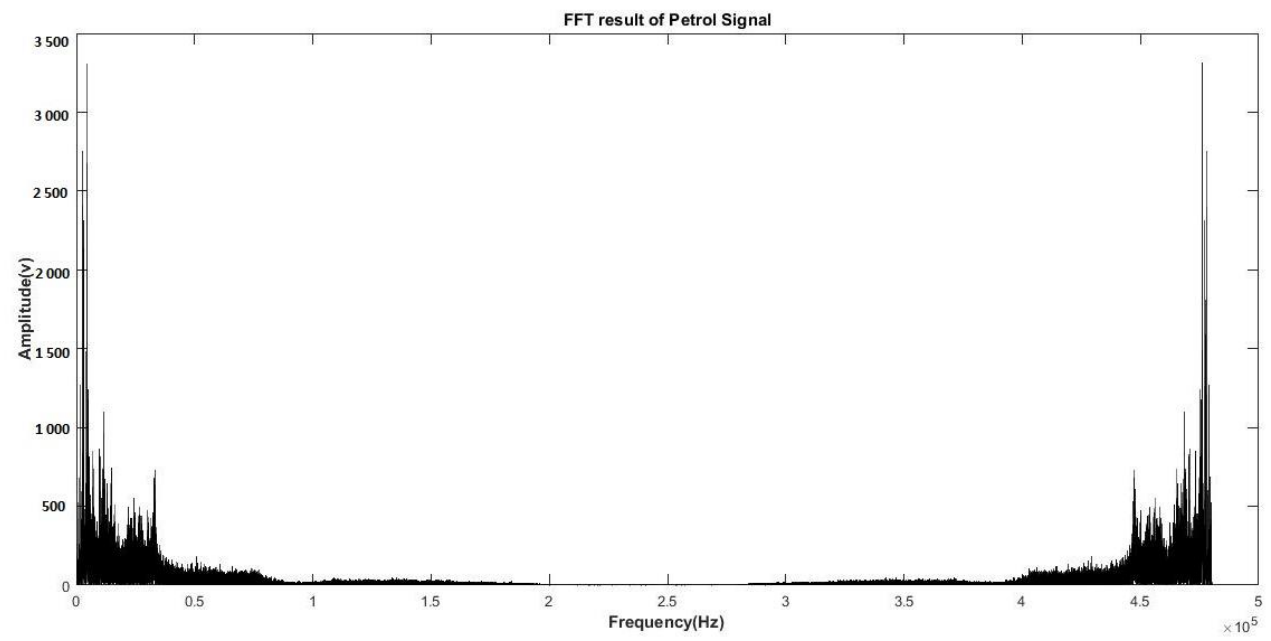

(a) FFT result of the Petrol Signal 


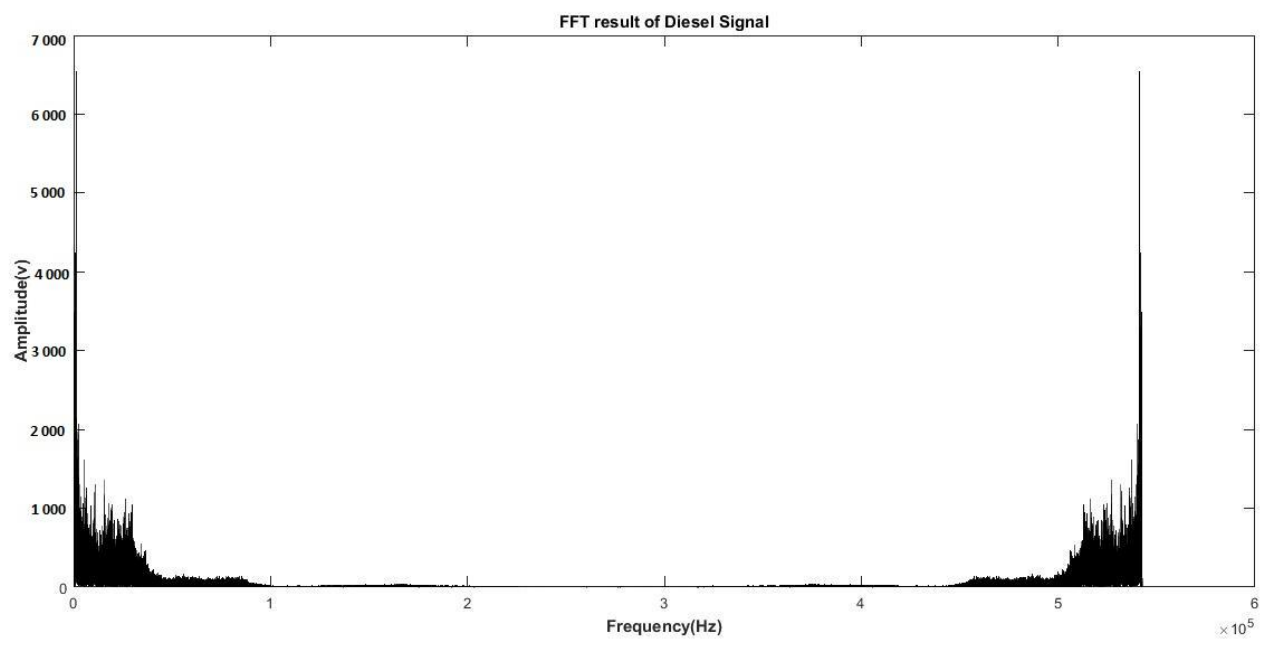

(b) FFT result of the Diesel Signal

Fig. 6. FFT result of the Petrol and Diesel Signal.

Table 3. experimental result of training and testing phase

\begin{tabular}{|l|l|l|}
\hline \multicolumn{1}{|c|}{ Type Classification } & Training (Classification rate \%) & Testing (Classification rate \%) \\
\hline Diesel & 100 & 100 \\
\hline Petrol & 100 & 100 \\
\hline
\end{tabular}

\subsection{Experiment analysis}

The distance between engine and microphone, noise environments and the stability of the sounds of the engine are affected to the recording quality. These factors impact the FFT algorithm. Table 3 discusses the accuracy between different types of petrol and diesel engine based on the sound of the engine. FFT algorithm feature extraction has applied as the feature extraction method. The result shows that the system has good accuracy, since it has $100 \%$ accuracy for both training and testing phases, respectively.

\section{Conclusion}

Misfueling diesel to petrol engine or petrol to diesel engine can cause fatal error in the engine system. These engines have different characteristics, the diesel engine has high compression ratio of its combustion chamber to ignite a mixture of diesel inside the chamber, while petrol engine uses spark plug to ignite a mixture of petrol in its much lower compression ratio combustion chamber. The working mechanism of each engine system fits to the chemical characteristic of the designated fuel, which will result in engine system damage if mis fuel. In this work, the intelligent system approach is used to automatically identify the type of engine based on the sound of the engine.

Support Vector Machines-based engine sounds identification has been proposed and discuss in this paper. The significant FFT frequencies used as features. The result shows that FFT frequencies have successfully performed as good features. The accuracy of the SVMs based engine sound identification using FFT frequencies is $100 \%$. Furthermore, the choice of the kernel function also affect on the performance of classification. The 
polynomial kernel function is the best kernel function implements in this system, since introducing a no misclassification classes.

\section{References}

1. Czlc, S.T.L.C. Datasheet 3138 - S Type Load Cell (0-100kg) - CZL301C, 1-4. [Online] from https://www.robotshop.com/media/files/pdf/datasheet-3138.pdf (2012). [Accessed on June 22, 2018]

2. V. Ilková, A. Ilka. (2017). Legal aspects of autonomous vehicles-an overview. Proceedings of the 2017 21st International Conference on Process Control (PC) (Štrbské Pleso, Slovakia, June 6 - 9, 2010). p. 428-433. http://publications.lib.chalmers.se/records/fulltext/249781/local_249781.pdf

3. J.P. Vishwanath, C.A. Meti, B.N. Shobha. SASTech, 8,1:93-100(2009). http://www.sastechjournal.com/pdf/Journals/April2009/13.pdf

4. World Economic Forum. ASEAN 4.0: What does the fourth industrial revolution mean for regional economic integration? Switzerland: World economic Forum (2017). p. 18. https://www.adb.org/sites/default/files/publication/379401/aseanfourth-industrial-revolution-rci.pdf

5. Kacira, A. Which is worse for the engine, putting diesel in a "petrol car" or petrol in a "diesel car"? [Online] from https://www.quora.com/Which-is-worse-for-theengine-putting-diesel-in-a-petrol-car-or-petrol-in-a-diesel-car (2014). [Accessed on June 22, 2018].

6. J.B. Sanchez. Speaker indentification based on an integrated system combining cepstral feature extraction and vector quantization. [Thesis] Department of Electrical and Computer Engineering, Florida State University, Florida (2005). http://diginole.lib.fsu.edu/islandora/object/fsu\%3A180337

7. N. Dave. International Journal for Advance Research in Engineering and Technology, 1,Vi:1-5(2013).

https://pdfs.semanticscholar.org/0b44/265790c6008622c0c3de2aa1aea3ca2e 7762. pdf

8. S.K. Mitra. Digital signal processing: A computer based approach. New York:

McGraw-Hill (2001) p. 807.

https://www.sciencedirect.com/science/article/abs/pii/S002626929800072X?via\% 3Dihub

9. J. Salomon. Support vector machines for phoneme classification. [Thesis] Master of Science School of Artificial Intelligence Division of Informatics, University of Edinburgh (2001). p. 1-73.

https://pdfs.semanticscholar.org/e107/6ed54ef5374d4a1676df1af1541247f75a83.p $\underline{\mathrm{df}}$

10. P. Potocnik. Neural networks: MATLAB examples. Lubjljana: University of Lubjljana (2012). $\quad$ http://lab.fs.uni-lj.si/lasin/wp/IMIT_files/neural/NNexamples.pdf

11. Wahyudi, W. Astuti, S. Mohamed. Journal of Computer Science, 3,5:274280(2007). https://www.thescipub.com/abstract/?doi=jcssp.2007.274.280

12. D. Gunawan, F.H. Juwono. Pengolahan sinyal digital dengan pemograman matlab [Digital signal processing with matlab programming]. Yogyakarta: Graha Ilmu (2012). p. 266. [in Bahasa Indonesia]. http://library.uny.ac.id/sirkulasi/index.php? $\mathrm{p}=$ show detail\&id=52445

13. S.O. Ogunlana, O. Olabode, S.A.A. Oluwadare, G.B. Iwasokun. (2015). Afr. J. Comp. \& ICT, 8,2:75-82(2015).

https://pdfs.semanticscholar.org/4259/6f3236d03f407abc04ed344264eadd671839. 
pdf

14. A. Nithya, R. Krithiga. IJPAM, 113,12:57-66(2017) https://acadpubl.eu/jsi/2017113-pp/articles/12/7.pdf

15. J. Sueuer. A very short introduction to sound analysis for those who like elephant trumpet calls or other wildlife sound. France: Mus'eum national d'Histoire naturelle (2018). https://cran.r-

project.org/web/packages/seewave/vignettes/seewave analysis.pdf

16. G. Valiente. Combinatorial pattern matching algorithms in computational biology using perl and r. London: Chapman and Hall, CRC (2017). p. 368. https://www.amazon.com/Combinatorial-Matching-Algorithms-ComputationalMathematical/dp/142006973X

17. S. Bilal, R. Akmeliawati, A.A. Shafie, M.J.E. Salami. Artif. Intell. Rev., 40,4:495516(2013). https://link.springer.com/article/10.1007\%2Fs10462-011-9292-0 